\title{
El ingeniero Calvi y la concepción de la Nueva Rhode: historia, arqueología e ingeniería militar en la Rosas renacentista*
}

\author{
LLUIS Buscató \\ PABLO dE LA FuENTE
}

\begin{abstract}
RESUMEN: SUMMARY:
Juan Bautista Calvi, ingeniero italiano al servicio de Carlos $V y$

Felipe II fue el diseñador de la moderna plaza fuerte de Rosas y

pionero del conocimiento

arqueológico de Rhode, su precedente urbano, una antigua colonia griega. La historia como lección práctica fue una herramienta utilizada por Calvi:

su idea relativa a Rhode y su

historia condicionó algunos aspectos de su proyecto, y la utilizó como argumento contra otros proyectos. Hoy en día, los hallazgos de Calvi nos permiten completar una visión entendedora de lo que fue la antigua Rhode

Giovanni Battista Calvi, Italian engineer who served the emperor Charles $V$ and his son Philip II, was who designed the modern fortification of Rosas in Catalonia and the pioneer of the archaeological knowledge of Rhode, urban precedent of this city, an ancient Greek settlement. History as practical lesson was a kind of tool used by Calvi: his concept about the ancient Rhode and its history conditioned some aspects of his project, and he used it as an argument against other projects. Nowadays, Calvi's archaeological discoveries allows us to complete an understanding view of the evolution of Rhode.
\end{abstract}

En marzo de 1553, el ingeniero Juan Bautista Calvi informaba con preocupación al secretario Francisco de Ledesma, que lo era del Consejo de Guerra, de la evolución de las obras de la plaza fuerte de Rosas 1 . Con una expresión casi constante de renovada fidelidad a quien reconoce como uno de sus protectores, Calvi manifiesta su molestia hacia los continuos retrasos habidos en la ejecución de las obras, aspecto que dificul-

- Las referencias a la actuación de Calvi en Rosas han sido tomadas, salvo expresa mención a partir de DE LA FUENTE, P., Les fortificacions reials del golf de Roses en època moderna, Roses, 1998, caps. $3,5,6,11,14$ y 17 .

1 Archivo General de Simancas, Estado, leg. 314, f. 5. 
taba el abandonar Rosas a fin de entender en la fortificación de otros lugares.

La intervención de Calvi en Rosas se vio jalonada de constantes obstáculos producidos por una enmarañada situación: la resistencia del país habida al cumplimiento de la Real Pragmática, los problemas financieros, las difíciles relaciones entre los oficiales reales y los poderes locales, agravadas por el asentamiento y alojamiento del presidio, las adversidades meteorológicas, e, incluso, los problemas de salud del propio Calvi, seriamente afectado de paludismo 2 . Este conjunto de serias adversidades no fue óbice para que Calvi dedique una sustancial parte de dicho informe a un hallazgo arqueológico habido al excavar el foso delante del baluarte de Santiago.

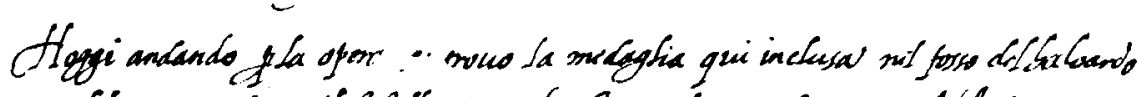

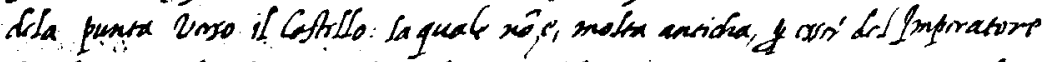

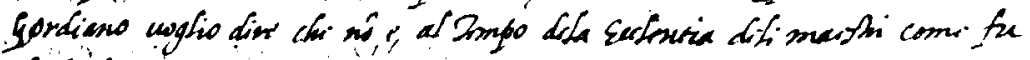

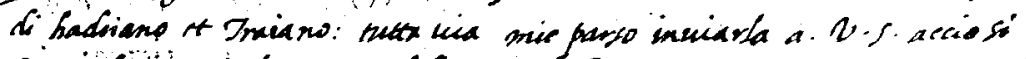

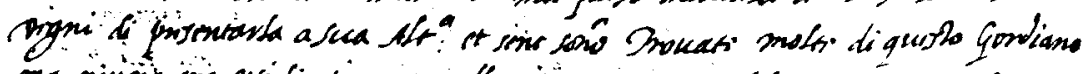

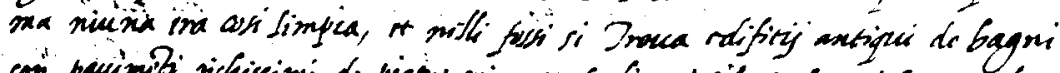

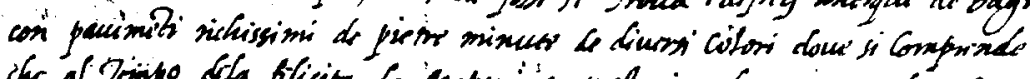

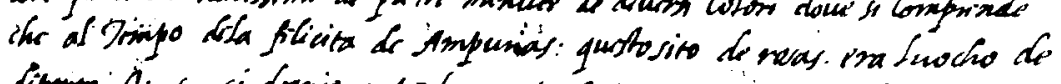

:

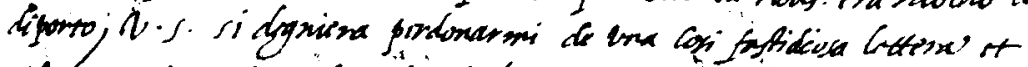

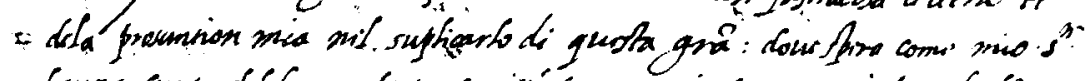

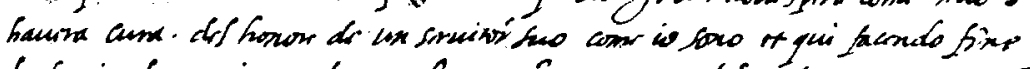
Sr Gascio lo meni it alasua bax goñ queneso fiu forto mi nace

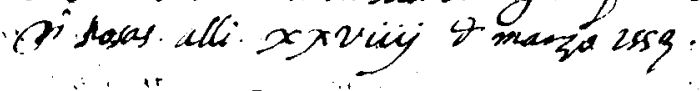

1) Fragmento de la carta remitida por Calvi al secretario Ledesma en que se describen los hallazgos arqueológicos materia de estudio (Archivo General de Simancas, Estado, legajo 314, folio 5)

2 Ibid., ibíd., leg. 314 , fs. 7 y 119-20; leg. 320 , fs. $2,5,6,11$ y $13 ;$ y Guerra Antigua, leg. 51 , f. 42 ; leg. 52 , f. 169, entre otros documentos, en donde hay claras alusiones al origen de su enfermedad y a los padecimientos de Calvi motivados por las crisis febriles. 


\section{JUAN BAUTISTA CALVI, PRIMER ARQUEÓLOGO DE RHODE}

Aunque la arqueología como ciencia auxiliar de la historia no adquirió una plena aceptación y madurez hasta la aparición de Heinrich Schliemann, los antecedentes de investigaciones históricas donde de una manera voluntaria, o más frecuentemente involuntaria, se ha utilizado la excavación de restos de antiguas civilizaciones como medio de obtención de datos para tratar de interpretar aspectos históricos poco o nada conocidos hunden sus raíces en el tiempo. Por ejemplo, algunos historiadores de época clásica, como el griego Tucídides en su Historia de la Guerra del Peloponeso 3 , obra del siglo $\vee$ a. C., ya utilizaron en sus obras datos obtenidos de esta forma, aunque los antiguos investigadores griegos y romanos no llegaron nunca a desarrollar técnicas específicas de recuperación o estudio y, en consecuencia, fueron incapaces de establecer una tradición de investigación arqueológica. Hubo pues que esperar al Renacimiento para que se pusieran los cimientos más antiguos de la actual ciencia arqueológica4. Ello fue debido a que durante este período se produjo un renovado interés por los textos literarios de la Antigüedad, lo que a la vez supuso un importante estímulo para la búsqueda de restos materiales, ya fuera para corroborar la localización de ciudades citadas en los textos, o para la de nutrir las colecciones de antigüedades tales como monedas, esculturas, inscripciones, etc. Los humanistas, armados con un amplio conocimiento de los clásicos, fueron los pioneros en la capacitación para comprender e interpretar el ingente volumen de restos que aparecian de nuevo a la luz. En el caso de la vecina Ampurias, por ejemplo, el obispo de Gerona Joan Margarit fue el primer autor conocido que a mediados del siglo Xv visitó las ruinas identificándolas con la antigua ciudad, lo que no evitó que el yacimiento siguiera siendo utilizado como cantera5.

Volviendo al texto que nos interesa, este queda muy lejos de una actual memoria de excavación, pero el ingeniero Calvi se nos presenta como un hombre con una vasta formación clásica, conocimiento que adquirió a través de la lectura de los textos. Sin embargo el carácter empirico propio del arqueólogo que demuestra en la carta entra en estrecha relación con su propia práctica profesional. Su labor como ingeniero militar y arquitecto civil en Roma 6 fue sin lugar a dudas su escuela arqueo-

3 I, VIII.

4 TRIGGUER, B G., Historia del pensamiento arqueológico, Barcelona, 1992, p. 39.

5 RUIZ DE ARBULO, J.; MAR, R., Ampurias romana. Historia, arquitectura y arqueologia, Sabadell, 1993, p. 50.

6 DE LA FUENTE, P., La fortalesa renaixentista de Roses: la intervenció de l'enginyer Calvi. Assaig sobre els projectes, les obres $i$ les realitzacions $i$ estudi valoratiu de les tècniques constructives, Consorci de la Costa Brava, 1993, p. 6. 


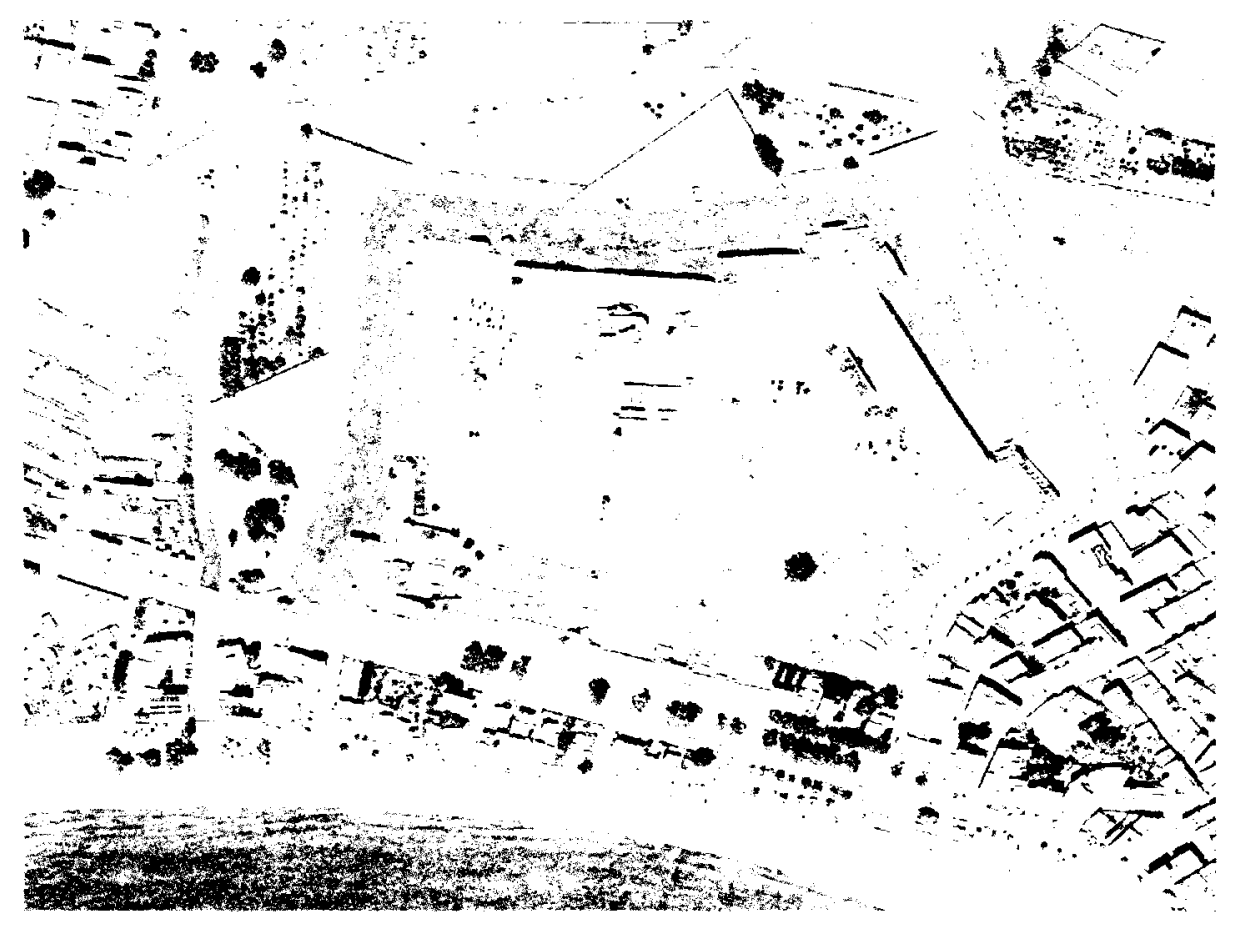

2) Vista aérea del área de la moderna plaza fuerte de Rosas:

1 Zona portuaria durante la Antigüedad grecorromana;

2 Área ocupada por la población medieval;

3 Baluarte de Santiago,

4 Turó de l'Escorxador

a Edificio " $A$ ";

b y c zona ocupada por necrópolis altomedievales;

d zona donde se localizaban los restos documentados por Calvi

lógica: los grandes movimientos de tierras y el reaprovechamiento de materiales, fue un contexto similar al encontrado en Rosas, donde incluso se llegó a reaprovechar la piedra de la vecina Ampurias. La prueba de su sólido conocimiento aparece en la capacidad y facilidad demostrada, ya que envía la carta el mismo día que realiza el hallazgo. Reconoce las monedas encontradas, pese a su deficiente estado de conservación, ya que afirma que "niuna era cosi limpia", identificándolas como monedas 
emitidas por el emperador Gordiano 1117 . Entiende la funcionalidad de las estructuras arquitectónicas aparecidas en el foso situado ante el citado baluarte, ya que es capaz de identificarlo como unas termas. Parece razonable que además de los "pavimenti richissimi di pietre minute di diversi colori», asumiera dicha conclusión al identificar otras estructuras que no le parecieron tan espectaculares como conductos de aire caliente, etc. Esta es la interpretación de Calvi de su hallazgo. ¿Cómo debe interpretarse el hallazgo a la vista de los actuales conocimientos existentes sobre Rosas en época romana? De las monedas poca cosa podemos decir excepto plantear si se trata de un atesoramiento voluntario o no. En el texto no se especifica el nivel de concentración del hallazgo. Calvi sólo se refiere a monedas de Gordiano III, no alude a otro tipo, lo que permite plantear la posibilidad de un atesoramiento voluntario. Tesoro que debió ser ocultado con posterioridad al reinado de este emperador, en torno a la segunda mitad del siglo III, época de gran inestabilidad política y económica8.

En cuanto al posible edificio termal localizado, cabe analizarlo a partir de los conocimientos arqueológicos existentes, ya que las fuentes de época clásica sobre el yacimiento son mínimas, casi inexistentes: de forma escueta informan que como consecuencia de la represión catoniana contra la revuelta indígena (195 a.C.) Rhode perdió su independencia y pasó a engrosar el ager de la vecina Ampurias9. Pomponio Mela, Claudio Ptolomeo y Esteban de Bizancio, autores de los siglos I, II y vi respectivamente, en sus obras sólo dan el nombre de la ciudad y describen brevemente su situación geográfica. La epigrafía, que parecía dar más información, ha resultado un fiasco: concretamente, una placa de mármol, encontrada en Cartago, que se había interpretado erróneamente referente a un municipio flavio en Rosas, es decir la concesión del derecho latino a la población durante la dinastía Flavia10. En cuanto a los restos arqueológicos de época romana conocidos actualmente en Rosas, estos son pocos y dispersos, lo que añade riqueza a la información de Calvi1t, dentro de un

7 En el documento se manifiesta su intención de «inviarla a V.S. [Ledesma] accio si digni di presentarla a Sua Alt [Felipe, en ese momento regente]", lo que induce a pensar que una de las monedas, la de mejor estado de conservación, fue enviada y, por lo tanto, hoy en dia podría localizarse en la colección de antigüedades del monarca.

8 DE MARTINO, F., Historia económica de la Roma antigua, Madrid, 1985, pp. 466 y ss.

9 TITO LIVIO, Ad urbe condita, XXXIV, 8, 4; ESTRABÓN, Geografia, XIV, 2,10.

10 PENA, M. J., "El municipio Flavio de Rhode: una hipótesis errónea», Homenatge a Miquel Tarradell, Barcelona, 1993, pp. 667-74.

11 NOLLA i BRUFAU, J. M.; CASAS, J., Carta arqueològica de les comarques de Girona. El poblament d'època romana al N. E de Catalunya, Girona, 1984, pp. 89 y ss. 
área situada entre el interior de la fortaleza renacentista y una zona más al norte y al este. Son destacables los siguientes yacimientos:

- La villa romana de Les Arenes, situada al norte de la fortificación trazada por Calvi, datada entre mediados del siglo ॥ y principios del I a.C., con un momento final en la segunda mitad del $1 / 12$.

- Los restos de muros, tumbas e incluso mosaicos y columnas, actualmente destruidos por el crecimiento urbano de la población al este de la fortificación, en la zona adyacente al paraje denominado el Turó de l'Escoxadori3.

- El denominado por los arqueólogos edificio $A$, localizado en el subsuelo del campo de la Coromina intramuros sobre la línea de mar antigua, el cual en origen ha sido interpretado como unas pequeñas termas del siglo $॥$, relacionadas con una cercana área portuaria 14 , posteriormente reformado hacia el segundo cuarto del siglo IV15, perdiendo su primitiva función, o por lo menos en parte, y transformándose en una factoría de salazones, siendo de la misma época tres pequeños depósitos, que han sido interpretados como cisternas de agua de suministro a las naves del puerto16, además de un muro, limítrofe a la muralla medieval, que presenta similitudes constructivas respecto a los muros del edificio $A 17$.

- Algo posteriores, entre los siglos IV y VIII 18 y también dentro de la fortificación renacentista, se localiza una necrópolis, dividida en dos sectores (el principal en el altozano de la Abadía y el secundario al

12 PALOL, P., “Descubrimiento e inicio de la excavación de una villa romana en el llano de Rosas", La labor de la Comisaria Provincial de Excavaciones Arqueológicas durante los años 1942-1948. Informes y memorias de la Comisaria General de Excavaciones, Madrid, 1952, pp. 159-62; VIEYRA $\mathrm{BOSCH}, \mathrm{G}$., "Excavacions arqueològiques a la vil.la romana de les Arenes, Roses (Alt Empordà), /I Jornades d'Arqueologia de les Comarques de Girona, Torroella de Montgrí, 1994, pp. 100-2.

13 RIURÓ, F., “Rhode i la colonització grega a la Mediterrània nord-occidental», Associació Arqueológica de Girona. Quadern de treball , 7, (1992), pp. 19-38

14 PUJOL, M., "L'emissari submari d'aigües residuals de Roses", Segones Jornades d'Arqueologia de les Comarques Gironines, Torroella de Montgri, 1994, pp. 87-92.

15 NIETO, X., El edificio “A» de la Ciudadela de Rosas. La terra sigillata africana, Girona, $1994, \mathrm{p} .188$.

16 lbidem, p. 186. PUIG, A. \& alii, «Resultats de la darrera campanya arqueològica realitzada a la ciutadella de Roses (Alt Empordà)", Segones Jornades d'Arqueologia de les Comarques de Girona, Torroella de Montgri, p. 158.

17 PUIG, A. \& alii, “La Roses d'època visigòtica en el subsòl de la Ciutadella (Alt Empordà): darreres investigacións", Annals de I'Institut d'Estudis Gironins, XXXVII, (1996), p. 1019

18 NOLLA i BRUFAU, J. M., «Roses a l'antiguitat tardana. El cementiri de Santa Maria», Annals de I'Institut d'Estudis Empordanesos, 30, (1997), p. 139. 
norte del edificio " $A$ " 19), y dos zonas de hábitat: una en el campo de la Coromina intramuros y la otra en el subsuelo de la villa medieval, datadas entre finales del siglo iv y el siglo VII20.

A partir de estos datos cabe plantearse qué se sabe realmente de la Rosas Alto y Bajo imperial. Ciertamente, poca cosa, visto que con anterioridad al siglo ॥ no se encuentra ningún resto estructural, aunque sí material, y hasta bien entrado el siglo Iv la única estructura de una cierta entidad es la fase II del edificio “A». En consecuencia, ante la pobreza de los restos que conforman un hábitat disperso y sin una clara estructuración urbanística, hay que aceptar la hipótesis planteada en un reciente trabajo, en que se identifica la Rosas tardoantigua con lo que San Isidoro de Sevilla denomina vicus 21: un lugar que sólo posee casas, sin construcciones comunales, es decir un área urbana sin entidad política, situación que se debia dar en época imperial cuando la población funcionó como un puerto secundario de la zona, utilizado básicamente en caso de mal tiempo22.

¿Cómo hay que interpretar las termas de Calvi en el contexto general de la zona?. Básicamente, a la luz de los datos existentes podemos plantear dos hipótesis:

- Nos encontramos ante un edificio de baños, ciertamente más rico que el localizado en la parte más antigua del edificio "A", la construcción del cual se ha de situar en un momento indeterminado del siglo IV, cuando el edificio «A» deja de funcionar como termas y se convierte en factoría de salazones, visto que no es factible que una población con tan poca entidad urbana como era la Rosas de la época pudiera mantener dos baños públicos a la vez. Los nuevos baños debían tener la misma funcionalidad que se supone originalmente al edificio " $A$ ": serían unas termas públicas que se relacionarían con la aneja zona portuaria. Incluso, cabe plantear si no fue la construcción de este nuevo edificio lo que motivó la transformación del edificio «A» y su conversión en factoría de salazones, visto que había llegado a ser innecesario.

19 NOLLA i BRUFAU, J. M.; AMICH, N. M., «El cementiri de l'àrea de l'hospital militar de la Ciutadella de Roses", Annals de I'Institut d'Estudis Gironins, XXXVII, (1996), pp. 1027-40; y NOLLA i BRUFAU, op. cit., pp. 107-46.

20 PUIG, A. «El jaciment de Rhode a la fi de l'antiguitat tardana. Els contextos del segle VIl d.C. a la Ciutadella de Roses (Alt Empordà, Girona)", Pyrenae, 29, (1998), pp. 171-92.

21 NOLLA i BRUFAU, op. cit., p. 144.

22 CASAS i GENOVER, J. \& alii., El món rural d'època romana a Catalunya. L'exemple del nord-est, Girona, 1995, p. 31. 
- Pero, por otro lado, resulta extraño que una aglomeración urbana de tan poca entidad como era la Rhode de época bajoimperial poseyera unos baños públicos de una cierta riqueza. Entonces, y como mera hipótesis, cabe plantearse si los restos que encontró no formaban parte de la pars urbana de la villa, que se situaria asi a una cierta distancia de los olores poco agradables que provocaba el hecho que en su pars rustica, el edificio A, se produjeran salazones de pescado23.

Por desgracia, la falta de datos más exactos, no olvidemos que los restos fueron totalmente destruidos poco después de ser descubiertos, no nos permite optar claramente por ninguna de las dos posibilidades ni ir más allá en la interpretación de la estructura localizada por Calvi.

\section{AD URBE CONDITA O LAS RAÍCES DE LA NUEVA RHODE}

Aunque el hallazgo cabe calificarlo como del todo casual, no lo es ni su interpretación ni el hecho que Calvi despache más de una tercera parte de su informe a la cuestión.

Por un lado Calvi lamenta y afirma que "no e molta anticha», en clara referencia a su cronologia bajoimperial, justificándose: "voglio dire che no al tempo... di hadriano et traiano". Dentro del contexto, la referencia a Adriano y Trajano no es ni mucho menos gratuita, pues propone una clara mimesis entre la monarquía española y estos emperadores romanos de origen hispano. Otra búsqueda de nexos similares se aprecia en una obra prácticamente coetánea como el famoso Carlos $v$ y el Furor, en la cual el Emperador encarna al héroe clásico24.

Calvi no sólo informa de los materiales arqueológicos, sino que además, como se ha expuesto, da una referencia bastante precisa del lugar del hallazgo que tampoco debe ser interpretada como anecdótica. Alude a la existencia de una estructura urbana antigua en el área del baluarte de Santiago, uno de los tres baluartes asentados en el ensanche de la Coromina. ¿Por qué?.

Uno de los puntos principales de debate de la actuación que llevó a hacer de Rosas uno de los conjuntos cualitativamente más importantes de Europa fue el planteamiento no sólo de su fortificación, sino también de su expansión urbana motivada por su interés estratégico que clara-

23 Más datos sobre las villas de época romana en el nordeste de Cataluña en CASAS \& alii, El món rural a època..., pp. 43 y ss.

24 MARIAS, F.; PEREDA, F., "Carlos V, las armas y las letras: introducción», Carlos V, las armas y las letras, Granada, 2000, pp. 33-4. 
mente se manifiesta en la potenciación de su puerto como base naval de tránsito e invernaje de las escuadras de galeras y las expectativas de incremento demográfico originadas por la implantación del presidio y los proyectos de población civil. Prever la expansión urbana suponía proyectar un perímetro fortificado mayor que el de la muralla bajomedieval de la villa, lo que significaba un importantísimo incremento en la cuantiosa inversión a realizar. El hecho que Calvi se decida a "ricorrere al aiuto" de Ledesma es del todo asociable al temor del ingeniero a una caida en desgraciada motivada por las difíciles circunstancias en la que se estaba dando su actuación.

Cuando Calvi intervino en Rosas, existian una serie de terraplenes y plataformas que años atrás el ingeniero Luis Pizaño había incorporado a la muralla medieval, una vez aplazado sine die su proyecto de una expandida plaza fuerte. A parte de la muerte de este ingeniero castellano y las razones técnicas citadas en anteriores trabajos, el abandono de sus proyectos post mortem puede también ser explicado a partir de las acusaciones que emergieron contra su persona25. Pese a ello, el forro de la obra ejecutada en 1544 era la actuación más rentable y que podía ahorrar un buen número de problemas políticos y económicos, ya que cabe añadir a lo dicho que la expansión significaba intervenir en la Coromina, tenencia de la abadia de Santa María.

El vital encuentro entre Alba y Calvi en Rosas en el verano de 1552 fue la clave de la luz verde a las diferentes ideas del ingeniero lombardo, cuestión refrendada en un posterior encuentro de Calvi con el futuro Felipe $\|$ en Monzón, que en ese momento asistía a las Cortes de los estados de la corona catalano-aragonesa.

Don Fernando Álvarez de Toledo, tercer duque de Alba, fue el más prestigioso soldado español que sirvió en los ejércitos de Carlos v y Felipe II, además de ser el más destacado consejero militar. No sólo fue un brillante combatiente, sino que además cabe considerarlo como un auténtico intelectual de la milicia. Del estudio de las actividades de Alba se desprende su impresionante conocimiento de la historia militar grecorromana y su veneración por algunos de sus personajes protagonistas. Una fuerte impresión pudo sentir don Fernando cuando tras la conquista de Túnez (1535) su señor Carlos v era aclamado como el Nuevo Escipión Africano, en honor a un claro paralelo con la conquista de la antigua Cartago26. La percepción de la Antigüedad desde la historiografía renacentista como, ante todo, la lección 
o el perfecto ejemplo por encima, incluso, de la veracidad intrínseca del hecho histórico27, tuvo su caldo de cultivo en la concepción del pensamiento militar y de la guerra en el Renacimiento, y también lo tendrá, tal y como se podrá apreciar, en la génesis de Rosas como moderna plaza fuerte. Siguiendo con el discurso relativo al gusto clasicista, la organización militar española toma claros préstamos: el tercio, principal unidad orgánica de la infantería española no deja de ser la plantilla de una legión romana reducida a una tercera parte28. Volviendo a la experiencia personal de Alba, éste parece ser disfrutaba en sus ratos libres con discusiones sobre historia militar antigua con sus oficiales adjuntos, siendo apreciable una profunda admiración hacía la figura de Julio César. Durante sus campañas en los Países Bajos, el asentamiento del Cuartel General de operaciones en Keiserlagen fue condicionado por su conocimiento que en aquel lugar, la antigua Castrum Caesaris, había senvido como campamento de Julio César en su campaña contra los belgas. A partir de aquí la analogía entre los antiguos belgas y los rebeldes holandeses y zelandeses está servida. Sin embargo, Alba no sólo tomó en cuenta los aspectos más épicos, sino que consideró como una seria referencia las experiencias bélicas. Cuando en una de las fases más críticas de sus campañas en Flandes su enemigo Orange vadeó el Maas, emergió el referente a los problemas durante la Guerra Civil del ejército cesariano en las complejas operaciones en el río Segre en la batalla de llerda29. Otra aportación en este sentido fue el plan de invasión de Inglaterra realizado por Alba a finales de los sesenta, con una operación de embarque y asalto anfibio en la costa de Kent basada en la campaña de César contra los Britanos 30 .

En el gusto de Calvi por la arqueología, la arquitectura y el urbanismo antiguo, y de Alba por la historia militar, cabe encontrar un referente común, una lección y ejemplo a seguir que creara la suficiente complicidad y sintonía entre ambos hombres, y un referente muy concreto que fuera la experiencia empírica tan propia del pensamiento renacentista. Este fue sin duda alguna el desembarco de las tropas de Marco Porcio Catón en Rhode en el 195 a.C. ${ }^{31}$, lo cual introduce automáticamente el debate en el tema de la visión de la ciudad antigua en el Renacimiento.

27 FONTANA, J., Historia: análisis del pasado y proyecto social, Barcelona, 1982, cap. 2.

28 DE LA FUENTE, P., "La guerra en el Renacimiento y en general en la Época Moderna en relación a las fortificaciones", El conjunto fortificado de Pamplona, (en prensa).

29 MALTBY, op. cit., p. 212.

30 DE LA FUENTE, P., «The Spanish Armada (1588) \& amphibious wartare: strategic concept \& tactical idea", (en preparación).

31 BUSCATÓ I SOMOZA, LI. La colònia grega de Rhode. Una aproximació al seu origen, evolució i desaparició, Roses, 1999, pp. 57-60 y 124. 
Calvi se remonta a la idealizada Antigüedad para justificar la envergadura de la actuación a partir del precedente histórico: «al tempo de la filicita di Ampurias" manifiesta que "questo sito di rosas era luocho di porto". En cierto modo, el proyecto de la plaza fuerte de Rosas se empapa del referente clásico, tanto a partir de aspectos globales como concretos. El vitrubianismo de Calvi se hace palpable en la concepción del modelo urbano: del famoso modelo de ciudad circular ideal de Vitrubio defendida por torres circulares32, a la adopción que la revolución militar renacentista hará de la planta pentagonal defendida por baluartes de igual forma geométrica, fenómeno que es el resultado del equilibrio empírico y teórico. También se aprecia esta herencia en el clasicismo arquitectónico de las dos puertas monumentales que Calvi proyectó para Rosas. La realización parcial de una y el abandono total de la otra podría llevar a la errónea creencia que Juan Bautista Calvi no proyectó la inclusión de elementos escultóricos. Si tomamos como referente las dos actuaciones de Calvi más cercanas, la puerta de Mar de Barcelona 33 y la de la Ciudadela de Perpiñán34, se aprecia la incorporación de cariátides y hermes a dichos conjuntos. En el caso de las cariátides, el origen de dichos elementos se halla recogido por Vitrubio35: en conmemoración de la victoria sobre la peloponesia ciudad de Caria, se mataron a todos los hombres y se llevaron a las matronas cautivas, sirviendo las figuras de esas mujeres como columna y ejemplo memorial del pecado de esa ciudad. En lo tocante a los hermes, también es el referente la cultura helena, aunque con un trasfondo más complejo36. Se hace más que difícil pensar que Calvi, que mostró este recurso como protagonista de su lenguaje arquitectónico en Cataluña, lo obviara en su proyecto para Rosas, la supuestamente primera ciudad helena fundada en la península Ibérica, ya que remonta su fundación a la primera Olimpíada, según autores de época clásica como Estrabón y Pseudo-Escimno37. Si en algún sitio estaba motivado dicho referente, éste era Rosas sin duda, aunque el hecho que el revestimiento monumental de ambas puertas hubiera de ser sufragado por la villa ampurdanesa, hizo que dicha operación quedara abortada por la compleja

32 MOROLLI, G. "Vitruvio e la città dei venti regolari. Istituzioni e invencioni della forma urbana del "De Architettura" e nell'esegesi degli interpreti classicisti del trattato", Architettura Militare nell'Europa del XVI secolo, Siena, pp. 299-336.

33 CÁMARA, A., "Murallas para la guerra y para la paz. Imágenes de la ciudad en la España del siglo XVI, Espacio, Tiempo y Forma. Historia del Arte, 6 (1993), pp. 154-5.

34 DE LAFUENTE, P., La ciudad como problema militar: Perpiñan y los ingenieros de la monarquía española (ss. XVI-XVII), Madrid, 1999, pp. 58-9.

35 CÁMARA, A., Fortificación y ciudad en los reinos de Felipe II, Madrid, 1998, p. 141.

36 DE LA FUENTE, P., "Perpinyà, baluard de Catalunya: la ciutadella de Felip //" (en preparación).

37 Cuestión recogida en BUSCATÓ, op. cit., p. 63. 
situación jurisdiccional de ésta y la falta de cooperación entre la Corona y el Condado de Ampurias, a la jurisdicción del cual estaba sujeta. Tanto las puertas monumentales de las fortificaciones como los retablos religiosos comparten lo que se podría definir como la búsqueda de una cierta emotividad del mensaje dentro una sugestión escenográfica. Es por ello creíble que en estos aspectos Calvi se viera auxiliado por otros artistas que dominaban estas técnicas compositivas. La posible implicación de Pere Serafí "Lo Grech" ya ha sido tratada. Precisamente el sobrenombre de este artista lo acerca al diseño y a la esencia narrativa de las cariátides barcelonesas o los hermes perpiñaneses. Cabe decir que no sólo Serafí colaboró con Calvi en este tema. Muy probablemente también lo hizo Pietro Paolo de Montalbergo, colaborador de Serafí y amigo personal de Fermo Calvi38. Precisamente el hecho que Montalbergo fuera el diseñador del retablo de la Resurrección de la iglesia de Sant Jaume de Vallespinosa, construida como mausoleo de Andreu de Biure ${ }^{39}$, primer capitán de Rosas y persona muy cercana a Calvi durante el período de construcción de la moderna plaza fuerte, vincula a este grupo de artistas a elementos del diseño de las inacabadas puertas de Rosas

\section{A MODO DE CONCLUSIÓN}

El resultado de toda la exposición es que Calvi quiso justificar el ensanche de Rosas tomando como referente el ejemplo que brindaba la antigua e idealizada Rhode. El hallazgo arqueológico de estructuras urbanas en el área del ensanche de la Coromina, si bien es casual, su interpretación fue más allá del tópico anticuarista y tuvo una esencial lectura histórica que se transformó en un producto elaborado del saber al servicio de una política de infraestructura estratégica. Tal y como se ha dicho, el hallazgo es casual y posterior a la definición del proyecto, lo cual no debe inducir a errores: es plausible pensar que Calvi tuviera predeterminada la idea que la extensión de Rhode fuera superior a la de la villa medieval, fundamentado en la idilica prosperidad que atribuye a la colonia rodia y la idea oscurantista que el pensamiento renacentista tenía del mundo medieval. El conocimiento del pasado se nos muestra como un elemento analítico de ese presente, y más aún, como factor clave del proyecto de futuro. En otras palabras, el proyecto de Calvi es de algún modo, la reivindicación de ese pasado, es una especie de Nueva Rhode.

$38 \mathrm{BOSCH}$ I BALLBONA, J. \& alii, De Flandes a Itàlia. El canvi de model en la pintura catalana del segle XVI: el bisbat de Girona, Girona, 1998, p. 211.

39 Ibidem, p. 130. 


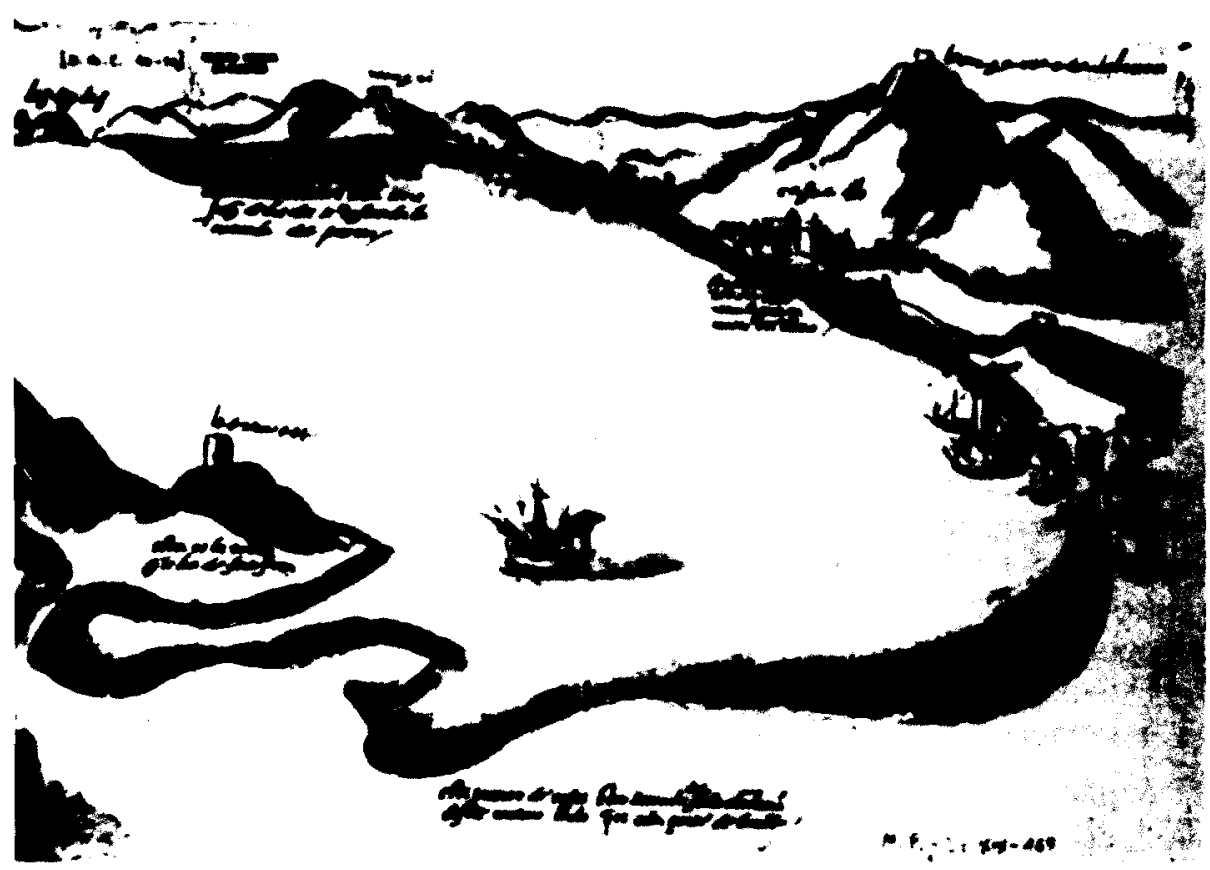

3) Vista del golfo de Rosas (1543) desde el puig Rom (Archivo General de Simancas, Mapas, Planos y Dibujos, XIX-168).

Dicho documento atestigua que dicha cota, identificada durante época moderna como el campamento de las tropas de Catón durante el sitio del 195 a.C., fue un punto de referencia clave en el momento de estudiar la fortificación de esta área.

Sin embargo, cabe substanciar el nexo propuesto hacia el pensamiento de Alba a partir de Catón. Un factor muy a tener en cuenta al mostrar la influencia historicista en el desarrollo de la fortificación de Rosas, es el conocimiento que se tenía de dicha operación militar. En este aspecto el papel de Jeroni Pujades 40 es fundamental. Además de cronista e historiador al que repetidamente alude la historiografía catalana, en este caso es relevante el hecho que Pujades fuera oficial administrativo del presidio de

40 Jeroni Pujades (Barcelona 1568- Castelló d'Empúries 1635), jurista e historiador, doctor en ambos derechos, fue profesor de cánones en la Universidad de Barcelona. De 1604 a 1609 trabajó para los condes de Ampúrias, primero como comisario general y asesor, y más tarde como abogado fiscal. Su obra más importante es la Crònica Universal del Principat de Catalunya, editada en Barcelona en 1609 . 
Rosas durante la primera mitad del siglo XVII. Pujades describe erróneamente las ruinas de un castrum visigodo en el Puig Romà41, sugestivo topónimo utilizado a mediados del siglo XV142, confundiéndolas con las del campamento que utilizaron las tropas de Catón tras desembarcar:

"Pero debemos persuadirnos que esta toma de Rosas no seria tan fácil como se pinta, sino que le costaría el batirla algunos dias; pues sacó la gente en tierra, asento su Real, é hízose fuerte en la montaña en la parte superior de la villa a la parte norte. Indican esto aquellas paredes asoladas y fundamentos de edificios que aun subsisten en el sitio que llaman Roma; reteniendo el nombre del ejército y del Real Romano que allí estuvo plantado; y atrévome á decir que por precisión le ha quedado este nombre con aquel motivo, pues en ninguna otra ocasión he hallado ejército romano tan poderoso como este sobre aquella plaza; y así es de creer que desde allí enviaba Caton sus escuadras sobre el pueblo, y a correr la campaña; y que desde allí tuvo á Rosas sitiada hasta que la rindió y entró: despues espelió los españoles que habia dentro, poniendo en su lugar soldados romanos»43.

Nuevamente el conocimiento histórico del momento, pese a su inexactitud, se transformó en un arma a favor de las ideas de Calvi que llegó a satisfacer los requerimientos historicistas de Alba. Si cuando Catón desembarcó ante la fortificada Rhode44, fijó su campamento en el Puig Rom o Romà, la lección que se derivaba en el siglo Xvi era una mordaz crítica hacia la anterior intervención de Pizaño y su castillo de la Trinidad, dominado por dicha cota. Pujades no era un experto en cuestiones militares, sino en derecho, por lo que es factible, vista la formulación de un juicio crítico, que fuera un recopilador de un saber ya existente, y que es fácilmente asociable a Alba. El impetuoso Duque ya intervino en 1543 cuando Pizaño se aplicó en su proyecto de fortificación. Precisamente, el único documento gráfico conservado de esos trabajos es una vista panorámica del golfo de Rosas, precisamente tomada desde el puig Rom. Tanto la sugerente toponimia como los restos de importantes estructuras fortificadas, y que fácilmente pueden ser consideradas como de esa épo$\mathrm{ca}$, fueron los elementos que indujeron al error.

41 PALOL, P., «Castro hispano visigodo de Puig Rom (Rosas), La labor de la Comisaria Provincial de Excavaciones Arqueológicas durante los años 1942-1948. Informes y memorias de la Comisaria General de Excavaciones, Madrid, 1952, pp. 163-182; NOLLA i BRUFAU, J. M., "Els objectes de vidre del Puig de les muralles (Puig Rom, Roses)», Empúries, núm. 51, (1998), pp. 237-249.

42 Archivo General de Simancas, Diversos de Castilla, leg. 40, doc. 10.

43 PUJADES, G., Crònica universal del Principado de Cataluña, Barcelona, reed. ,1830, tomo II, p. 12. 44 BUSCATÓ, op. cit., p. 60 
Los hechos posteriores ilustran que la opinión de Calvi no iba desencaminada. Durante el sitio de 1794-5, el asentamiento de baterías francesas en el Puig Rom, fue un factor determinante en la resolución del asedio al hacer del todo insostenible la resistencia de la Trinidad. A este respecto, las críticas documentadas de Calvi sobre el castillo de la Trinidad llegan a ser despiadadas: la defensa debía concentrarse en Rosas y desmantelar el castillo. Aunque no se llegó a ese punto, Calvi consiguió plenos poderes para hacer y deshacer con respecto a Rosas, llegando a modificar su propio proyecto originario sin el beneplácito de la Corte.

Como colofón, cabe afirmar que a la vista de estos hechos resulta lógica la importancia que Calvi dio al hallazgo, que no lo olvidemos está dentro de una situación poco halagüeña respecto a la ejecución de las obras de fortificación de Rosas. Calvi incide en el descubrimiento de las estructuras arqueológicas para conseguir así, mediante argumentos históricos, reafirmarse en que la decisión de cambiar totalmente el proyecto era correcta. Es decir, aunque la localización del edificio de baños romanos, como ya se ha comentado, fue totalmente casual, no perdió la oportunidad de utilizar un argumento histórico como éste para favorecer su propia concepción de la obra. 
